\title{
BARES PÉ-NA-AREIA E A FAROFADA NA PRAIA: UMA ANÁLISE DURKHEIMIANA DAS DISTINÇÕES PÚBLICO/ GRATUITO-PRIVADO/PAGO NO LITORAL DE ARACAUU-SE
}

\author{
BEACH BARS AND PICNIC AT THE BEACH: A DURKHEIMIAN \\ ANALYSIS OF THE DISTINCTIONS BETWEEN PUBLIC/FREE OF \\ CHARGE AND PRIVATE/PAID ON THE COAST OF ARACAJU/SE
}

\author{
Marina de Souza Sartore*
}

Introdução

0 Brasil é um país que possui uma grande extensão litorânea, com mais de 7.367 mil quilômetros ${ }^{1}$, e com $26,6 \%$ de sua população morando em municípios da zona costeira ${ }^{2}$. No entanto, as praias, enquanto objeto de estudo, costumam ser negligenciadas pelos profissionais da Sociologia. Esta afırmação é evidenciada na introdução do dossiê $P l a-$ ges, territoires contestés, da revista francesa Actes de la Recherche en Sciences Sociales, dedicado aos estudos sociológicos do litoral
(BIDET; DEVIENNE, 2017). Particulamente, os sociólogos tendem a deixar os estudos sobre a ocupação mercadológica do litoral para economistas e geógrafos. Em Sergipe, estes estudos consistem em análises prescritivas, tais como o diagnóstico do nível de educação ambiental costeira de empreedendores e consumidores (PROVINCIALI; SARAIVA; 2009), a avaliação de prestação de serviços, com uso de tecnologias em bares e restaurantes (BEZERRA; SILVA, 2013), e o grau de desenvolvimento turístico do litoral (LIMA; VILAR, 2014).

\footnotetext{
* Professora e pesquisadora na Universidade Federal de Sergipe - UFS - (Aracaju/SE/Brasil). Doutora em Ciências Sociais. E-mail : marinasartore.ufs@gmail.com

1. Informação disponível em <https://educacao.uol.com.br/disciplinas/geografia/litoral-brasileiro-costatem-grande-importancia-e-deve-ser-preservada.htm>. Acesso em 08 de Janeiro de 2019.

2. Informação disponivel em <http://www.brasil.gov.br/noticias/seguranca-e-justica/2011/12/ibge-e-marinha-lancam-atlas-geografico-das-zonas-costeiras-e-oceanicas $>$. Acesso em 08 de Janeiro de 2019. 0s dados se referem ao censo do IBGE de 2010.
} 
Neste artigo, desenvolvo uma análise sociológica ${ }^{3}$ da ocupação mercadológica da praia pelos bares pé-na-areia, que são bares e restaurantes construídos sobre a faixa de areia em frente ao mar. Argumento que dois fenômenos social e geograficamente situados ocorrem nas praias da cidade de Aracaju: o primeiro, a festa popular; e o segundo, em oposição ao primeiro, a festa privada. A análise sociológica sobre estes dois fenômenos dialoga com a conceituação de festa (1968 [1912]) e de propriedade privada (1950 [1890-1900]) do sociólogo Émile Durkheim.

0 uso do termo festa popular é inspirado no conceito de baile popular, que significa "um espaço de aproximação de corpos instituído - um espaço de contatos, de sensações, de excitações, de prazeres no qual a livre expressão é amplamente autorizada” (URBAIN, 2016 [1994], p.155). 0 artigo 10, da lei 7.661/88 da Constituição Federal Brasileira, garante o livre e franco acesso às praias e ao mar (BRASIL, citado por CASTRO; SOUTO, 2010), pois as praias são propriedade do Estado. Nas praias de Aracaju, principalmente na Zona de Expansão Urbana (ZEU), a festa popular ocorre em espaços com acesso público e gratuito, onde se reúnem diversos grupos sociais que usam vestimentas como o maiô, o biquíni, sunga e interagem uns com os outros mediados pelo compartilhamento de refeições e bebidas, seja na forma de churrasco, piquenique, aperitivo ou tira-gosto ${ }^{4}$. Assim, temos todos os elementos que compõem a festa: a vestimenta, a comida, a bebida e a interação entre as pessoas em um momento de descontração e prazer, que pode ser mediado também pela música ${ }^{5}$.

A partir da década de 70, no Brasil, o processo de expansão do turismo Sol e Praia consolidou-se (CASTRO; SOUTO, 2010), culminando no desenvolvimento do turismo de massa, invadindo as praias da região nordeste, as quais se consagraram como o principal destino de turismo de Sol e Praia no país ${ }^{6}$. As praias passaram a receber uma infraestrutura urbana na forma

3. Os dados empíricos coletados advêm de: (a) entrevistas realizadas com 16 dos quase 50 proprietários de bares pé-na-areia situados na zona de expansão urbana de Aracaju, durante o período de Janeiro a Maio de 2017. Todas as entrevistas foram transcritas; (b) 100 avaliações do bar pé-na-areia melhor ranqueado no TripAdvisor, cobrindo o período de Dezembro de 2014 a Janeiro de 2017. Cem (100) avaliações do segundo bar pé-na-areia melhor ranqueado no TripAdvisor, cobrindo o período de Outubro de 2011 a Fevereiro de 2017. 0 método de análise destas 200 avaliações está descrito em "autor do texto" (2017); (c) 138 fotografias que acompanham as 200 avaliações do TripAdvisor, analisadas observando-se os enquadramentos e o conteúdo de cada enquadramento, agrupando-os e classificando-os em categorias de análise; (d) 24 reportagens publicadas no jornal Infonet, selecionado por ser o jornal local de Aracaju. 0 período abarca os anos de 2008 a 2015. As 24 reportagens ajudaram na reconstituição histórica do processo de demolição dos bares da praia de Aruãna, em Aracaju.

4. Informações adquiridas via método de observação direta, realizada ao longo de 2017.

5. Em observação direta, realizada ao longo de 2017, verifiquei o uso eventual de veículos com caixas de som ou o uso de caixinhas de sons portáteis.

6. Dados retirados da pesquisa de Hábitos de Consumo do Turismo Brasileiro 2007 a 2009, citados por Castro e Souto (2010). 
de condomínios de segunda residência, resorts, bares pé-na-areia, restaurantes, etc. (cf. LOLOUM, 2015, para o caso de Tibau do Sul, no Rio Grande do Norte).

No caso de Aracaju, existe a Orla de Atalaia, localizada ao longo da Avenida Santos Dumont, que corresponde ao trecho de orla urbana, revitalizada na década de 90 (PEREIRA, 2013), de maneira que os bares e restaurantes foram alocados sobre a orla, deixando o espaço da faixa de areia da praia praticamente vazio. A cidade de Aracaju também conta com um trecho de mais ou menos 20 quilômetros de litoral (Zona de Expansão Urbana - ZEU), cuja intensificação da ocupação urbana iniciou-se no final dos anos 70, consolidando-se com a lei municipal 873/1982. A ocupação urbana da ZEU foi facilitada pela construção da Rodovia José Sarney ${ }^{\overline{7}}$ em 1984 (FRANÇA, 2011), ao longo da qual estão distribuídos 48 bares e restaurantes pé-na-areia, também conhecidos como Bares da Sarney (Figura 01).

Neste artigo, argumento que o desenvolvimento destes bares reflete a festa privada na praia, através da qual turistas e moradores-frequentadores usufruem da praia, sobre a faixa de areia, intermediados por um empreendimento privado, voltado ao lazer e para a compra de comida e bebidas (Figura 02).

Figura 01 - Localização geográfica dos bares pé-na areia na Zona de Expansão Urbana de Aracaju

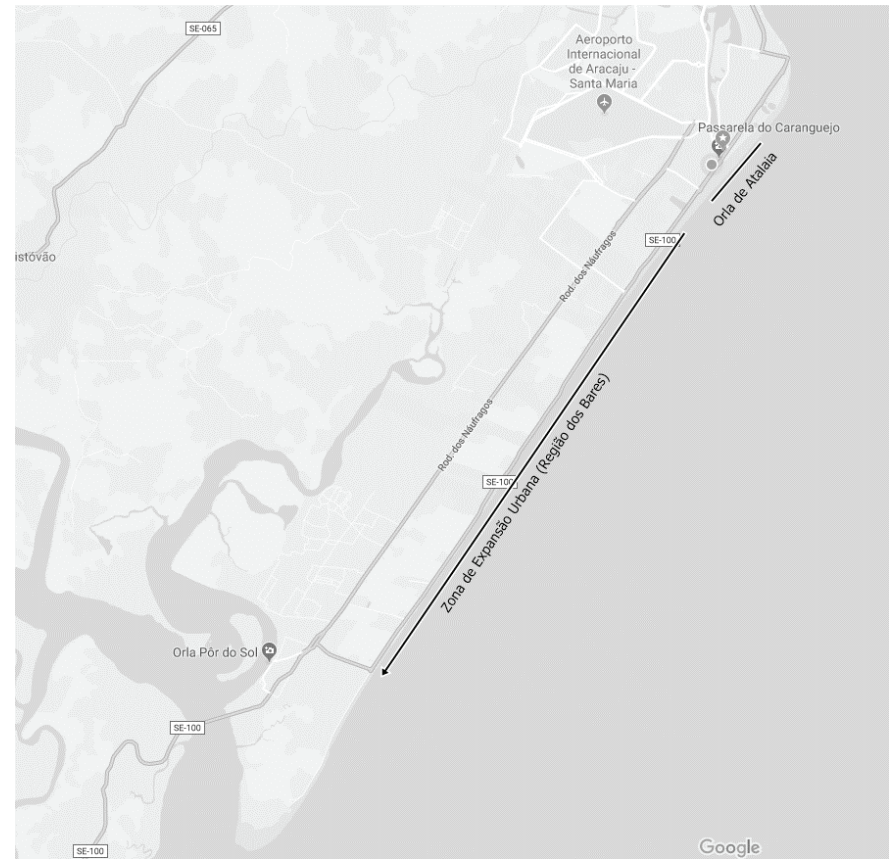

Fonte: Imagem retirada do Google Maps. Sinalização feita pela autora. 


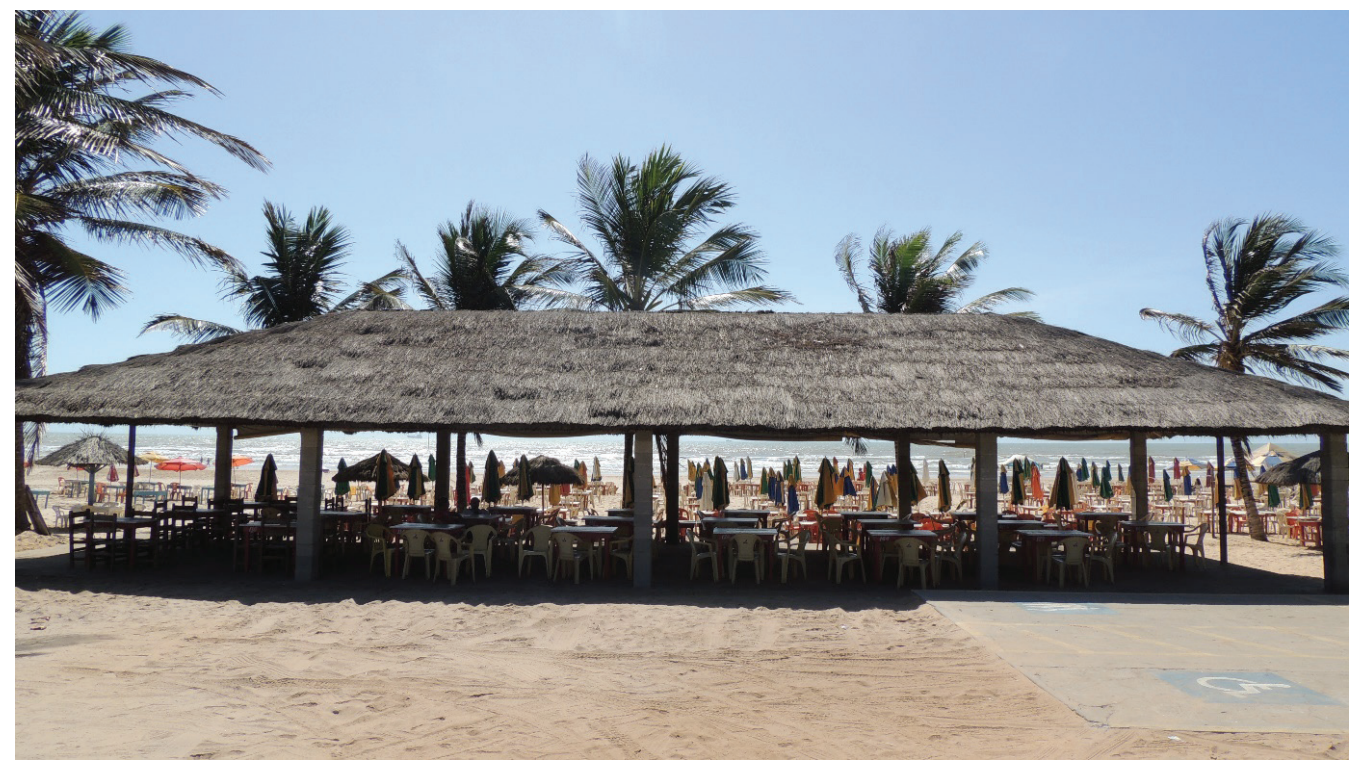

Fonte: Arquivo pessoal

0 surgimento e expansão dos bares péna-areia criam um novo uso da praia intermediado por transações econômicas, o qual chamo de festa privada, que se opõe à festa popular. De um lado, a festa popular pressupõe o uso gratuito e público da praia, enquanto a festa privada o seu uso pago e privado. Porém, tanto a festa popular, conhecida popularmente como farofada, como a festa privada, na forma dos bares pé-na-areia, podem ser consideradas "festa”. 0 dono de um dos bares pé-na-areia se expressa neste sentido: "quando eles [os clientes fiéis] vão embora eu digo, se vocês não voltarem, a festa não continua, então vocês têm que estar sempre aqui para a festa continuar" (Trecho de Entrevista com Proprietário do Bar 02).

A argumentação deste artigo se divide da seguinte maneira: na parte 01 , caracterizo a praia enquanto festa popular, dialogando com as reflexões de Durkheim (1968 [1912]) sobre a festa enquanto um “espaço/ tempo de distanciamento da vida ordiná- ria" que ocorre "sem fins utilitários". $\mathrm{Na}$ parte 02, caracterizo a existência dos bares pé-na-areia como a festa privada na praia, a partir dos eixos de análise "espaço/tempo de distanciamento da vida ordinária” e “negação dos fins utilitários", particularmente, para três grupos que participam da festa privada: os turistas, os moradoresfrequentadores e os proprietários dos bares pé-na-areia. A partir deste primeiro eixo argumentativo, concluo que, no caso dos bares pé-na-areia, a oposição bem definida apresentada por Durkheim entre vida ordinária associada ao mercado versus o estado de efervercência sem fins utilitários se torna mais tênue, reconfigurando a oposição gratuito versus pago.

Depois da reflexão inspirada em Durkheim sobre a praia enquanto espaço de festa, desenvolvo, na parte 3 , o segundo eixo argumentativo, inspirado na explicação de Durkheim (1950 [1890-1900]) sobre o respeito à propriedade privada. Argumento que o respeito à festa popular advém 
da construção social do respeito à praia enquanto espaço público e gratuito, e o seu uso privado revela a tensão pela definição da relação entre o mercado e o meio-ambiente pelo Estado. Como ilustração para o meu argumento, trago o fenômeno das demolições dos bares pé-na-areia, que expressa o embate entre o uso público ou privado da praia, e que se complexifica quando consideramos os três grupos que participam do fenômeno da festa privada na praia: os turistas, os frequentadores-moradores e os proprietários dos bares pé-na-areia, somando-se também o Estado. A partir destes dois eixos argumentativos, busco demonstrar na conclusão o profícuo diáologo com E. Durkheim para realizar uma Sociologia Econômica da Praia, analisando os usos da praia em Aracaju por estes dois fenômenos, que expressam duas representações coletivas $^{8}$ opostas (Durkheim, 1898): a festa popular e a festa privada, que revelam os limites, por vezes difusos, entre a questão do gratuito versus o pago e do público versus o privado.

\section{A praia como um espaço de festa: diálogo com Émile Durkheim}

\subsection{A praia enquanto festa popular e sua oposição à festa privada}

Com o intuito de aproximar o estudo sobre a praia com a sociologia durkheimiana, argumento que o uso da praia na
Zona de Expansão Urbana (ZEU) de Aracaju enquanto festa popular é análoga à ideia de festa trabalhada por Durkheim (1968[1912]) em dois sentidos principais: (1) pelo afastamento do cotidiano e (2) pela evocação de uma alegria pública sem fim utilitário, esta última chamada pelo autor de corrobbori vulgaire.

Durkheim (1968 [1912]) analisa as tribos australianas e argumenta que existe uma relação de continuidade entre os rituais religiosos e a festa. Os rituais religiosos evocam os totens e são dramatizados por pessoas selecionadas, ocorrendo em um espaço específico e em datas excepcionais. Para o autor, os rituais religiosos, afastados da vida ordinária, adquirem uma efervercência social que possui o efeito de integrar a sociedade. Em outras palavras, os rituais religiosos afastam o grupo de sua realidade laboral e ordinária, pois "estranhos a todo fim utilitário, eles [os rituais] fazem os homens esquecerem o mundo real, para lhes transportar a outro, no qual a sua imaginação é mais aguda: eles distraem” (p.362). Os rituais religiosos se constituem em um espaço aberto para a liberdade criativa quando o grupo participante pode dançar, cantar e se entregar à efervescência daquele momento, propiciando uma forma de revitalização, mediante o breve afastamento da vida ordinária, cotidiana e profana.

Segundo Durkheim (1968 [1912]), os rituais religiosos, quando transferidos para um outro local, não mais sagrado e onde

8. A representação coletiva é considerada por Durkheim como a trama resultante das relações entre os indivíduos que ganha autonomia tornando-se externa a eles. A representação coletiva se impõe aos indivíduos na forma de crenças, de práticas religiosas, de regras morais, de preceitos jurídicos, ou seja, de "todas as formas mais características da vida coletiva [...] que são expressamente obrigações” (DURKHEIM, 1898, p. 17). 
todos podem participar, se transformam em um rito de festa, alcançando o estado de corrobbori vulgaire, que consiste na "simples alegria pública na qual não há mais nada de religioso e da qual todos podem indiferentemente tomar parte" (p.362). Assim, a linha que separa o estado de efervercência provocado pelo ritual religioso e o estado de efervercência provocado pelo rito da festa é tênue, sendo difícil distinguir o momento de transmutação do primeiro para o segundo. Para o autor, os rituais religiosos evocam a ideia de festa e vice e versa, pois mesmo que a festa seja puramente laica em suas origens, ela tem certas características do ritual religioso, porque ela tem por efeito aproximar os indivíduos, colocar em movimento as massas e suscitar, assim, um estado de efervescência, às vezes mesmo de delírio, que possui parentesco com o estado religioso. Ambos, o ritual religioso em maior grau e a festa em menor grau, ao mesmo tempo em que afastam o grupo de sua vida laboral ordinária, desempenham o papel de reforçar a seriedade da vida cotidiana e de revitalizar o conjunto do coletivo.

0 uso da praia na Zona de Expansão Urbana (ZEU) em Aracaju, caracterizado como festa popular, se assemelha à noção de festa explicitada por Durkheim (1968 [1912]). Durante um período específico, que consiste principalmente na alta temporada, as praias da ZEU em Aracaju são invadi- das por usuários (turistas e moradores-frequentadores) que ali buscam uma fuga do cotidiano de trabalho ${ }^{9}$. A necessidade da fuga do cotidiano faz com que o indivíduo comum viaje e se torne um turista, em um espaço longe de sua casa. Uma vez turista, o indivíduo sente a necessidade de retornar ao cotidiano, transmutando-se novamente em indivíduo comum. Este movimento, indivíduo comum - turista - indivíduo comum, é chamado por Krippendorf, (2003 [2001]) de ciclo da reconstituição do indivíduo, que opera pelo mesmo modo que a reconstituição dos laços sociais da vida ordinária pelos ritos religiosos e pela festa. A festa popular na praia se opõe à esfera da vida laboral cotidiana, pois representa um espaço e uma temporalidade oposta a ela ${ }^{10}$.

Além do afastamento do cotidiano, a festa popular na praia da ZEU em Aracaju se assemelha à ideia de festa trabalhada em Durkheim (1968 [1912]), pois causa um estado de efervercência mais próximo da ideia de corrobbori vulgaire, em que há "a simples alegria pública (...) onde todos podem indiferentemente tomar parte" (Durkheim, 1968 [1912] p.362). Reúne-se a família, os amigos, por vezes leva-se uma churrasqueira para providenciar a comida e um isopor com bebidas, sendo a cerveja a mais popular ${ }^{11}$. Este fenômeno recebe 0 nome popular de farofada, que implica na realização de uma reunião na qual se leva a comida e a bebida.

9. A discussão sobre a contextualização da recreação como uma fuga do cotidiano e oposição ao trabalho é muito presente no campo do lazer (uma abordagem histórica sobre essas relações pode ser encontrada em Marinho e Pimentel (2010) e no campo do turismo (Krippendorf, 2003 [2001])).

10. Para uma discussão sobre a vivência da praia no contra tempo e no contra espaço, ver Sebilau, 2018.

11. Dados obtidos por observação de campo 
A praia vista como um espaço de festa popular nos permite caracterizá-la a partir de elementos de recreação, uma vez que os rituais referentes aos usos da praia implicam em um afastamento da vida ordinária: usa-se roupas que não são normalmente utilizadas na vida ordinária de trabalho, busca-se a contemplação, o riso, a diversão, sendo o espaço de expressão da simples alegria pública que, por sua vez, fortalece os laços sociais e reforça a seriedade da vida cotidiana.

Em suma, ir à praia na ZEU para comer e beber em Aracaju é análogo a ir a uma festa popular, pois (1) corresponde a um ritual de efervescência social, sem fim utilitário e que evoca a recreação; (2) evoca o distanciamento da vida ordinária relacionada ao trabalho, ao mesmo tempo em que reforça a vida ordinária laboral; e (3) possui os elementos característicos de uma festa: a reunião do grupo, a comida, a bebida e, por vezes, até a música. No entanto, se por um lado, a ida à praia para beber e comer consiste em uma festa popular sem fim utilitário, onde todos do grupo podem participar, vivenciando uma alegria e distração pública, por outro, a existência dos bares pé-na-areia na ZEU de Aracaju tem sido palco de uma outra representação coletiva, a qual chamo de festa privada na praia.

Tanto a festa popular quanto a festa privada contam com as características da reunião do grupo, da existência de comida, bebida e, por vezes, a música. No entanto, estes dois fenômenos se diferenciam em dois pares de oposição: o primeiro, o gratuito e o pago - a festa popular não é intermediada por transações econômicas ${ }^{12}$, enquanto a festa privada pressupõe serviços intermediados pelo dinheiro, como compra e venda de comida, bebida e aluguel de mesas e cadeiras ${ }^{13}$; o segundo, o público e o privado - enquanto na festa popular o coletivo tem livre acesso à praia, podendo livremente escolher onde fincará o seu guarda sol, na festa privada existem impedimentos materiais e simbólicos que coíbem o acesso à praia, como estacionamento privado, a estética do local, a ocupação da areia da praia com cadeiras, mesas e guarda-sóis, os preços do cardápio, etc.

Enquanto o grupo da festa popular alcança o estado de corrobbori vulgaire na relação entre si e com a praia, o grupo que frequenta os bares pé-na-areia, ou seja, que frequenta a festa privada, alcança o estado de corrobbori vulgaire intermediados por transações econômicas de serviços oferecidos pelos proprietários dos bares e os seus

\footnotetext{
12. Não se pode ignorar a existência de ambulantes que circulam também livremente nas praias. Assim, poderíamos estar diante de um contínuum entre o acesso livre à praia no qual o grupo leva a sua própria comida e bebida, o acesso livre no qual o grupo pode optar por comprar comida e bebida de ambulantes, e o acesso privado no qual o grupo se insere imperativamente em uma relação econômica de compra e venda. 13. 0 caso de Praia Grande, em Ubatuba-SP, é emblemático: o estreito espaço de areia é ocupado por mesas e cadeiras de bares que solicitam uma caução de até $\mathrm{R} \$ 150,00$ para que o usuário possa usufruir de sua estrutura (mesas e cadeiras), ao mesmo tempo em que garantem a renda do bar. Informação disponível em: < http://www1.folha.uol.com.br/cotidiano/2017/11/1932033-contra-farofada-quiosques-cobram-caucao-de-ate-r-150-no-litoral-de-sp.shtml>. Acesso em 30 de Janeiro de 2018.
} 
trabalhadores. Na próxima seção, problematizo esta distinção entre a festa popular na praia, que pressupõe uma interação gratuita e pública, e a festa privada, na qual necessariamente o grupo usufui da praia intermediado por transações econômicas em um espaço exclusivo.

\subsection{A festa privada: A diminuição e ocul- tação do econômico}

Para Durkheim (1968 [1912]), a festa, que ocorre no âmbito do sagrado, estaria em oposição à vida laboral e ao mercado, que ocorrem no âmbito do profano. Em outras palavras, a festa estaria associada a um evento de caráter excepcional, no tempo e no espaço, em oposição ao cotidiano do trabalho, não podendo coexistir na mesma unidade do tempo. Seguindo este argumento, a festa se opõe ao trabalho e, consequentemente, ao mercado. Por exemplo, Crozat e Fournier (2005) apontam que grande parte da literatura sobre o mercado do turismo o considera como um fenômeno de mercado, profano, opondo-se à ordem sagrada da festa. No entanto, contra-argumento que os bares pé-na-areia reconfiguram e complexificam esta oposição entre o rito da festa e o rito do trabalho/mercado, principalmente, quando consideramos os seus participantes, que se distribuem em três tipos: o turista, o morador-frequentador e os produtores da festa (proprietários dos bares, funcionários, fornecedores ${ }^{14}$ ).

Um primeiro eixo de análise diz respeito ao distanciamento da vida cotidiana. Para um turista, a ida ao bar pé-na-areia possui o caráter temporal e geográfico excepcional, pois está usufruindo de suas férias longe de casa e, consequentemente, longe de seu cotidiano de trabalho. No entanto, para o morador-frequentador, o caráter temporal e geográfico é menos excepcional e mais dinâmico, uma vez que circula entre as esferas do trabalho e a dos bares pé-na-areia com maior frequência. Um dos proprietários afirma que, em seu bar, os frequentadores são majoritariamente moradores da região e diz: "eu comecei aqui, eu fui fazendo amizades com eles e foi passando de um para o outro, mais ou menos uns 90\% do condomínio [situado do outro lado da rodovia em frente ao bar] frequentam aqui o nosso bar" (Trecho de Entrevista com Proprietário do Bar 06).

Se considerarmos os proprietários dos bares e seus funcionários, o caráter temporal e geográfico excepcional sobrepõe o tempo de trabalho no tempo da alta temporada, ou seja, trata-se de seu cotidiano de trabalho que se intensifica justamente no período de festas, de alta temporada, quando há mais turistas.

\footnotetext{
Meio agora de fevereiro, por exemplo, começam as aulas dia 16, cai o movimento. Aí começa a vir o carnaval, aí começa a melhorar de novo. E aí vai indo né? É meio que igual a formiga, nós trabalha (sic.) no verão para comer no inverno. Devagarzinho né. Tem que saber controlar os gastos, porque se não você pira (Trecho de Entrevista com Proprietário do Bar 10).
} 
Assim, a reconfiguração da relação festa versus mercado depende destes três níveis de afastamento do quotidiano: o do turista, separando trabalho e vida ordinária; o do morador-frequentador, oscilando mais frequentemente entre estas duas esferas; e, por fim, o do proprietário e seus funcionários, sobrepondo estas duas esferas. Estas três lógicas de relação com a temporalidade da festa convivem no espaço da praia de Aracaju.

O segundo eixo de reflexão trata do fim utilitário da festa: a festa privada ocorre em um espaço e temporalidade intermediados por transações econômicas, o que, hipoteticamente, corromperia o estado público de alegria sem fim utilitário, o corrobbori vulgaire. Afinal, todos os bares da Sarney, cujos proprietários entrevistamos, são de propriedade privada do tipo familiar e que almejam o lucro, ou uma renda familiar. Estes bares pertencem ao campo econômico, regido pela lógica do "negócios são negócios”, na qual os frequentadores da praia são vistos como clientes, as refeições são vistas como produtos/serviços, os atendentes como funcionários, todos trabalhando e produzindo essa festa privada (fornecedores, garçons, cozinheiras e faxineiras). 0 próprio bar seria visto como um empreendimento cuja execução de um plano de negócios aumentaria a sua rentabilidade. 0 uso da praia passa a ser intermediado, majoritariamente, por relações de consumo. Assim, tudo se passa como se a festa pública fosse substituída pela privada e o gratuito fosse substituído pelo pago.

o [Bar 11] é uma empresa com departamento de recursos humanos, com finanças, com a produção de cozinha, com a compra de carne, com tudo né? É uma pequena empresa (...) o [Bar 11] não é um bar na praia, o [Bar 11] é uma empresa. Primeiro é uma empresa, depois é um bar da praia. Está entendendo? (Trecho de

Entrevista com Proprietário do Bar 11).

Em um primeiro momento, tudo se passa como se a festa privada expressasse a pura ocupação mercadológica da praia, orientada tanto pela demanda quanto pela oferta. Mas, quando se analisa os discursos de turistas e moradores-frequentadores, o aspecto econômico se associa ao de felicidade e, no caso dos proprietários dos bares pé-na-areia, o aspecto econômico é apresentado como um ato econômico desinteressado (BOURDIEU, 2017 [1992-1993]).

Quanto aos turistas e moradores-frequentadores, há uma associação entre momentos de felicidade e a infraestrutura de consumo provida pelos bares pé-na-areia. Em uma análise de conteúdo de duzentas avaliações online sobre 2 bares pé-na-areia da ZEU de Aracaju, escritas e publicadas na plataforma online TripAdvisor, majoritariamente por turistas e moradores-frequentadores (SARTORE, 2017), observei que o destaque era para a qualidade e o sabor da comida, a cordialidade do serviço e a limpeza do local, ou seja, elementos contratuais que estão objetivados em leis e normas de higiene de estabelecimentos comerciais, normas de qualidade no atendimento e de serviços ao consumidor que garantem a satisfação de uma relação comercial. Em seguida, as informações mais destacadas se relacionam ao "não contratual do contrato" (sobre este conceito, ver Durkheim, 1999 [1893]), ou seja, por questões de ordem da moral, enfatizando a experiência vivida. Dentre as informações menos citadas, está o preço dos produtos e serviços, ou seja, quanto se está pagando pela experiência. Em outras palavras, o discurso presente na avaliação qualitativa (escrita) destes bares 
apesenta uma forte associação entre contentamento e a boa experiência vivida com a comida, o atendimento e a estrutura do local.

Essa forte associação fica mais evidente a partir da análise de 138 fotografias publicadas junto às avaliações escritas na plataforma TripAdvisor. Cinquenta e seis fotos retratam a infraestrutura do bar, incluindo fotos do bar com o mar ao fundo; quarenta e quatro retratam a comida e a bebida, algumas vezes com o mar ao fundo. Se, por um lado, a maior parte das fotos apresenta a estrutura do bar, a comida e a bebida, por vezes acompanhados do cenário litorâneo, por outro, apenas 08 fotos apresentam o cardápio com os preços, e apenas 10 fotos retratam exclusivamente a natureza ao redor. Esses dados fotográficos mostram que na escolha tanto das fotos a serem publicadas para que outros viajantes vejam o local, como os seus enquadramentos que transmitem momentos de felicidade, destacam-se o consumo de comida e de bebidas (normalmente alcoólicas) em uma estrutura de bar, sendo este o principal elemento de distinção do uso da praia como festa privada em relação à festa popular.

Figura 03 - Exemplo de postagem TripAdvisor demonstrando a comida, a bebida, a estrutura do bar e o mar ao fundo.

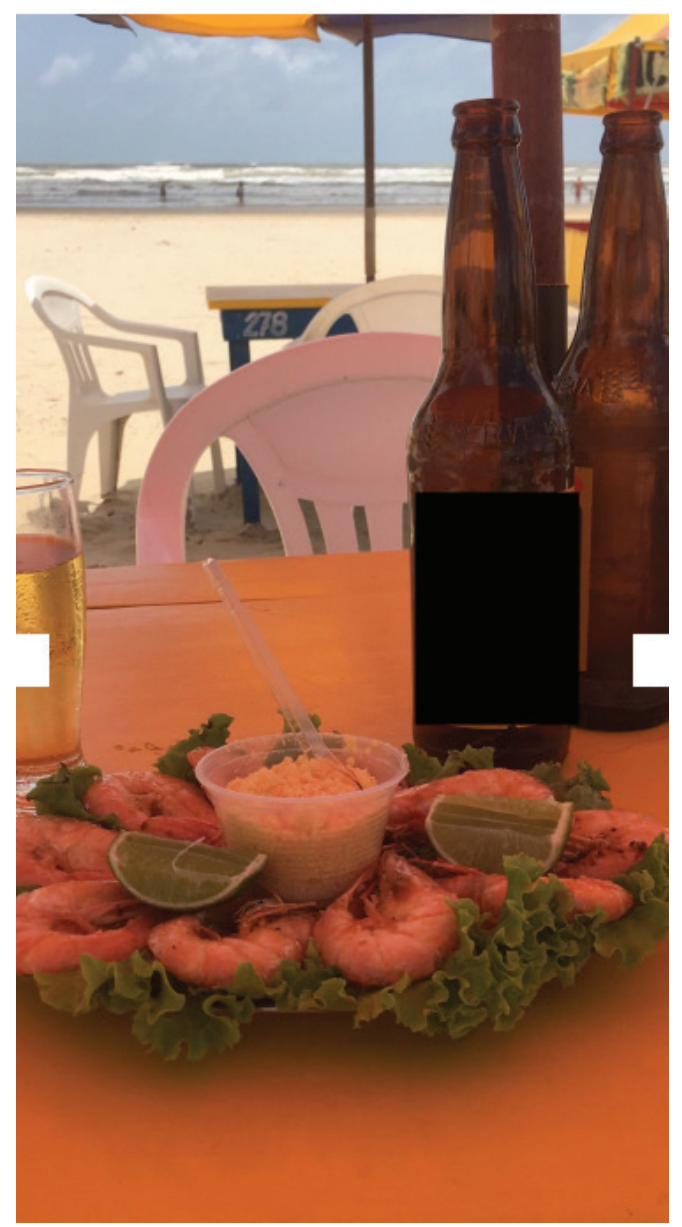

Fonte: TripAdvisor. As fotos foram salvas e numeradas para compor o banco de dados para análise. Esta é a foto 09. 
A análise das avaliações do TripAdvisor, assim como das fotografias publicadas, permite afirmar que, apesar da menor ênfase dada às transações comerciais (preços) da festa privada, há uma forte associação entre as avaliações com os elementos contratuais do mercado de alimentação fora de casa que, se bem executados, produzem uma boa experiência vivida e uma avaliação positiva. Se a orquestração não ocorre, o resultado é uma avaliação negativa. Importante ressaltar que, como observa Cardon (2014), as notas das avaliações no TripAdvisor possuem uma média elevada (3,8 de 5,0), levando o autor a concluir que a plataforma é bastante utilizada para "testemunhar experiências felizes de consumo”. Assim, tanto pelas avaliações online escritas, quanto pelas fotografias postadas, é possível verificar uma crescente associação de uma positivação das experiências no bar pé-na-areia com potencial de girar o pêndulo da alegria pública da festa popular para a alegria da festa privada como uma forma dominante de uso da praia como festa. Assim, a recreação e a alegria objetivadas em avaliações positivas se associam a um espaço de consumo, passando por um processo de ressacralização via mercado, similar ao evidenciado por Zelizer (1992), para o caso do seguro de vida.

Do lado dos proprietários dos bares, o interesse econômico aparece na forma de uma denegação do interesse econômico (BOURDIEU, 1977). Por exemplo, o proprietário do Bar 11, que em um primeiro momento retrata o bar como uma empresa, posteriormente afirma: "nosso serviço é felicidade, isso é que é a nossa proposta, por isso que fız também o réveillon, o réveillon eu não fız para ganhar dinheiro, eu fiz porque eu gosto (...) Então eu gosto de ver as pessoas felizes. Eu gosto de ver as pessoas rindo".

A denegação do interesse econômico pela maior parte dos proprietários dos bares pé-na-areia não ocorre de maneira consciente, pois é resultado das disposições adquiridas em suas histórias de vida. No caso dos proprietários de bares pé-na-areia na ZEU de Aracaju que foram entrevistados na pesquisa, mais da metade possui o bar há mais de 15 anos. Assim, há em seus discursos uma forte associação entre o bar e a própria casa, onde se recebe amigos ${ }^{15} \mathrm{e}$ não consumidores, sendo que, no caso dos Bares da Sarney, muitos sobrevivem devido aos clientes amigos e fiéis. Por exemplo, o proprietário do bar 02 afirma: "além de tudo eu tenho fregueses, eu tenho uns amigos, eu fiz muita amizade e geralmente sempre quando não vem um, vem outro e você vai sobrevivendo e assim é a vida"; de maneira similar, o proprietário do bar 05 afirma: "Rapaz, não porque assim, como nós somos um dos primeiros bar aqui nós temos nossa clientela fidelizada, chega cliente? Chega, mas a maioria são clientes fiéis, antigos”; e o proprietário do bar 10: "Aqui eu não tenho cliente, eu tenho amigos”.

0 desinteresse econômico aparece na evocação do bar como a vida do proprietário ${ }^{16}$, fundindo a esfera da vida doméstica

15. Este discurso está presente em 11 das 16 entrevistas.

16. Este discurso está presente em 09 das 16 entrevistas. 
e a do trabalho. Por exemplo, o proprietário do bar 02, quando perguntado se o bar já fazia parte da sua história, responde: “já, já faz parte do meu DNA aqui e acabou dentro do meu sangue e até os meus amigos dizem, rapaz, não sei como vai ser o dia quando você não estiver mais aqui”; de maneira similiar, o proprietário do bar 05 diz: “É, a nossa história de vida é essa aqui mesmo, a gente nasceu aqui, viveu aqui, sobrevive aqui durante esses 30 anos e sobrevivemos daqui”.

Por fim, o desinteresse econômico aparece pela associação do bar como um espaço de felicidade ${ }^{17}$, por exemplo: "Rapaz, eu gosto muito do que eu faço, eu conheço muita gente, eu faço boas amizades, então eu gosto muito do que eu faço, eu trabalho muito feliz, muito alegre, muito bom" (Trecho de Entrevista com Proprietário do Bar 06).

Assim, o fim utilitário da festa privada na praia aparece como um ato desinteressado. As lógicas da produção econômica da festa privada se desenrolam tanto pela associação crescente entre mercado e festa, por parte dos turistas e moradores-frequentadores, quanto pela denegação do interesse econômico, do lado dos proprietários dos bares pé-na-areia.

\section{Festa privada: o conflito entre mercado e meio-ambiente}

A praia é pública e gratuita. Pública, porque pertence ao Estado e a todos os cidadãos brasileiros. Gratuita, porque o seu acesso é livre, não pago. Mas, para que a praia, enquanto um espaço natural, seja pública e gratuita, foi necessário que se construísse e se compartilhasse a crença de que a natureza é pública, gratuita e de propriedade de todos, portanto, do Estado. Durkheim (1950 [1890-1900]) possui uma teoria sobre como construímos e compartilhamos desta crença. Segundo ele, em nossa construção de mundo a natureza pertence à humanidade. Porém, existem coisas que não pertencem à humanidade, porque pertencem aos deuses e são respeitadas por todos que compartilham desta ideia. Segundo Durkheim (1950 [1890-1900]), a fonte do respeito à propriedade privada se iniciou na esfera do sagrado, pois "são as operações rituais que criam ao redor do campo e da casa uma faixa que os deixa sagrados, ou seja, invioláveis, salvo por aqueles que operam a sacralização" (DURKHEIM, 1950 [1890-1900], p.117). Durkheim embasa este argumento pela descrição sobre a propriedade na época medieval por Fustel de Colanges, e exemplifica com a descrição do ato sagrado de cavar uma fossa ao redor da propriedade, colocar ervas, flores, oferendas, pedaços de pedra e de madeira que delimitavam o espaço privado, legitimado pelo ritual sagrado.

Esta base religiosa vai aos poucos sendo substituída pela crença sagrada na própria sociedade, representada pelo Estado. Atualmente, tanto o respeito pela propriedade privada quanto pelo bem público perpassam pelo respeito que temos ao que é ourtogado pelo Estado como sendo público ou privado. 0 espaço da praia é público e

17. Este discurso está presente em 08 das 16 entrevistas. 
gratuito porque é do Estado e isto está escrito na forma de lei; mas, o que garante o respeito ao público e ao gratuito é a nossa crença no Estado enquanto guardião do bem público, garantindo o acesso universal e gratuito a estes espaços. Uso Durkheim (1950 [1890-1900]) para afirmar que a noção de festa popular, ou seja, da praia como um espaço público e gratuito, é mantida pelo nosso respeito pela crença compartilhada de que o Estado é o guardião sagrado de tudo aquilo que consideramos público e gratuito, inclusive a natureza ${ }^{18}$. Por isso, o caso da demolição dos bares pé-na-areia em Aracaju na ZEU é um exemplo que aponta para uma das roupagens atuais do debate sobre os limites entre o público e o privado.

\subsection{Público + Natureza versus Privado + Mercado: os limites ilustrados a partir do caso das demolições dos bares pé-na- areia em Aracaju}

A construção de bares pé-na-areia representa uma apropriação privada do espaço da praia que é público. Mais recentemente, a ocupação das praias por bares e restaurantes tem sido colocada em xeque em diversas regiões do Brasil, como Salvador [Após demolições, Salvador chega ao sexto verão sem barracas na orla ${ }^{19}$, Porto Seguro [MPF pede demolição de barraca de praia em Porto Seguro na Bahia ${ }^{20}$, Santa Catarina [Juiz manda demolir resort de luxo e "beach clubs" em Florianópolis ${ }^{21}$ ], São Paulo [Guarujá demole quiosques, sorteia novos pontos e deixa turistas confusos ${ }^{22}$ ]. Estas notícias são exemplos de demolições, ou de tentativas de demolição, decorrentes da execução de políticas públicas avindas do projeto ORLA ${ }^{23}$, do Governo Federal, que busca o ordenamento dos espaços litorâneos sob domínio da União ${ }^{24}$. Em Aracaju, na praia de Aruã-

18. Este cenário já vem encontrando mudanças com a crescente aceitação da sociedade em precificar bens não precificáveis. Para uma análise sociológica do tema, ver Fourcade (2011).

19. Disponível em: <http://www1.folha.uol.com.br/cotidiano/2017/01/1849997-apos-demolicoes-salvador-chega-ao-sexto-verao-sem-barracas-na-orla.shtml>. Publicado em 15.01.2017. Acesso em 21 de Dezembro de 2017.

20. Disponivel em <http://leniojornalismo.blogspot.fr/2017/01/mpf-pede-demolicao-de-barraca-de-praia. html>. Publicado em 29.01.2017 Acesso em 29 de Janeiro de 2017.

21. Disponivel em <https://istoe.com.br/juiz-manda-demolir-resort-de-luxo-e-beach-clubs-em-florianopolis/>. Publicado em 22 de Junho de 2017. Acesso em 21 de Dezembro de 2017.

22. Disponivel em <http://m.folha.uol.com.br/cotidiano/2018/01/1950484-guaruja-demole-quiosquessorteia-novos-pontos-e-deixa-turistas-confusos.shtml>. Acesso em 15 de Janeiro de 2018.

23. Disponivel em: <http://www.mma.gov.br/gestao-territorial/gerenciamento-costeiro/projeto-orla?>. Acesso em 15 de Janeiro de 2018.

24. Um caso similar é relatado por Bruno e Salle (2017) sobre a praia de Pampelonne, uma praia de St Tropez, na França. Segundo os autores, a praia passou a sofrer as influencias da loi littoral desde 1986, culminando em um abaixo-assinado dos estabelecimentos comerciais para que não sejam removidos do local. 
na, localizada na ZEU, ao menos 16 bares pé-na-areia foram demolidos em $2008^{25}$. As demolições foram autorizadas pela Justiça Federal em favor de ação conjunta entre o Ministério Público Federal em Sergipe (MPF/ $\mathrm{SE}$ ), a Advocacia-Geral da União (AGU), o Instituto Brasileiro do Meio Ambiente e dos Recursos Naturais Renováveis (IBAMA) e a Secretaria do Patrimônio da União (SPU), que argumentaram que os bares pé-na-areia agridem o meio-ambiente, não seguem a legislação trabalhista e ocupam o espaço de maneira irregular e ilegal ${ }^{26}$.

Os 48 bares da Sarney estão sendo processados pelo Ministério Público Federal desde $2014^{27}$ [MPF ajuiza ação contra 65 bares da Atalaia e Sarney], sob alegação de irregularidade de funcionamento, além da ocupação irregular em área de proteção ambiental. Em 2015, os bares da Sarney conquistaram na justiça o direito de manterem os seus estabelecimentos funcionando e fazerem adequações em suas estrutu$\operatorname{ras}^{28}$. A análise de 24 reportagens sobre os processos de demolição dos bares da praia de Aruana e dos bares da Sarney do jornal Infonet, publicadas ao longo dos anos de 2008 a 2015, evidenciam que o argumento predominante em prol da demolição dos bares pé-na-areia é de cunho ambiental, acusando os proprietários dos bares pé-na-areia de agredirem o meio ambiente ao se instalarem em área de proteção ambiental.

A linguagem ambiental objetiva uma disputa simbólica do que representa este espaço de festa privada em detrimento da festa popular. De um lado, o Estado, através do Ministério Público, argumenta que os bares estão instalados em terreno que não é deles e que desrespeitam as leis ambientais. Do lado dos proprietários, a disputa ganha uma roupagem econômica ao argumentarem que geram renda, emprego, entretenimento, infraestrutura para o turista e moradores da região ${ }^{29}$. Segundo um dos proprietários dos bares entrevistados,

Eles [o poder público] não entendem que turismo
é fonte de renda, e fica querendo agora, diz que
eu sou um agressor da natureza, quer dizer, onde
construíram esses condomínios aqui não são
agressores, é tudo barão. Eu sou um agressor. Eu
sou um agressor? Eu gero divertimento, eu gero
renda pro município, emprego aqui pro pessoal,
movimento a economia do comércio (Trecho de
Entrevista com Proprietário do Bar 14).

Um outro proprietário busca uma solução intermediária na qual haveriam espaços tanto para o seu bar quanto para os "farofeiros" da festa popular:

Vem muita gente do interior, como a gente chama "os farofeiros" eles gostam de chegar,

25. "Mais nove bares serão demolidos na Aruana" - por Glauco Vinícius e Carla Sousa. Jornal Infonet, 25 de Junho de 2008.

26. "MPF defınirá na próxima semana a demolição dos bares da Aruana". Jornal Infonet, 19 de Junho de 2008. 27. "MPF ajuíza ação contra 65 bares da Atalaia e Sarney” Jornal Infonet. 18 de Novembro de 2014.

28. "Bares da praia conquistam vitória da justiça”. Jornal Infonet. 02 de Abril de 2015.

29. Vídeo "Mais de 60 bares localizados na orla de Aracaju podem ser demolidos" disponível em: <https:// www.youtube.com/watch?v=4JvWvmeNOQM>. Acesso em 05 de setembro de 2017. 
entrar, mas eu acho que ainda aqui deveria, por mais espaço que Aracaju tenha, tem que fazer um local, para poder eles ter (sic.) as paradas deles, as redes deles, coisas deles lá, ficarem lá (Trecho de Entrevista com Proprietário do Bar 02).

No Brasil, é possível observar algumas reações coletivamente organizadas quando a população se vê diante de uma ameaça ao uso público da praia e do direito de fazer uma "farofa". Em Itajaí, em Santa Catarina, um grupo de 400 pessoas se reuniram na praia para farofar e se manifestar "contra um dono de bar que xingou e perseguiu uma frequentadora da praia" (ALVES, 2016). Em 2015, moradores dos subúrbios do Rio de Janeiro fizeram uma manifestação em favor da farofada, quando as linhas de ônibus que ligavam seus bairros à praia foram cortadas (CMI BRASIL, 2015).

Do lado dos usuários das barracas de praia, o trabalho de Vera, Ladeira e Costa (2013) explicita que a percepção dos usuários da praia de Salvador ${ }^{30}$ sobre a retirada das barracas representou uma queda na qualidade dos serviços prestados. No caso de Aracaju, em especial a região de Aruana, houve uma manifestação por parte dos usuários dos serviços dos bares pé-na-a- reia contra a demolição [Frequentadores da Aruana são contra derrubada de bares ${ }^{31}$.

A polêmica sobre o uso privado da praia se repete em outras localidades do Brasil. Nos casos da Praia Grande, em Ubatuba, e da Praia Brava, em Itajaí, a justiça limitou o número de mesas e cadeiras ${ }^{32}$ que podem ser colocadas na praia pelos bares, possibilitando que haja espaço para aqueles que buscam fazer a festa popular na praia.

Inspirada na argumentação de Durkheim sobre a fonte do respeito à propriedade privada, argumento que acompanhar esta disputa argumentativa, de um lado, pelo argumento ambiental do Estado e, de outro, pelo argumento econômico dos proprietários dos bares, é acompanhar a disputa sobre qual versão deve prevalecer de uso da praia: a festa popular ou a festa privada. Compreender as dinâmicas contemporâneas da fonte do respeito à propriedade pública e do respeito aos usos privados é compreender os limites da força sagrada do Estado, que são delineados na esfera jurídica do Estado.

Este contencioso político e jurídico traz o debate sobre o valor moral atribuído ao uso público ou privado da natureza e sua dinâmica merece ser melhor investigada, principalmente pela ótica da forma como

30. Não foram encontrados dados sobre a percepção do turista de Aracaju sobre a possibilidade de demolição dos bares da Sarney.

31. Informação disponível em: <http://www.infonet.com.br/noticias/cidade/ler.asp?id=74857>. Acesso em 06 de Fev. 2018.

32. Para o caso de Ubatuba, ver: <https://g1.globo.com/sp/vale-do-paraiba-regiao/noticia/acordo-najustica-limita-mesas-e-cadeiras-de-quiosques-nas-praias-em-ubatuba.ghtml >. Para o caso de Itajaí, ver: $<$ https://diarinho.com.br/noticias/geral/prefeitura-flagra-o-abuso-de-bares-e-restaurantes/>. Acessos em 06 de Fev. 2018. 
o Estado busca manter o seu status de "sagrado”, garantindo a fonte do respeito à propriedade pública e privada. Dependendo de quem vencer esta disputa, intermediada no âmbito do Estado, a demolição dos bares será considerada moralmente boa ou ruim, uma modernização ou um retrocesso.

\section{Considerações finais}

A própria existência do bar pé-na-areia em Aracaju evidencia as reconfigurações da praia como um espaço de festa popular e festa privada. Esta é uma regressão sociológica, na medida em que busca compreender fenômenos mais gerais da sociedade, tais como os processos de ocupação privada do litoral brasileiro e as reconfigurações dos limites entre o público/gratuito e do privado/pago a partir do caso particular dos bares pé-na-areia de Aracaju.

Um dos principais objetivos deste artigo foi o de caracterizar a ida à praia, para consumir bebidas e comidas, como um espaço de festa, caracterizado pelas representações coletivas da festa popular e da festa privada, dando ênfase para a segunda. As leituras sobre a festa e sobre as fontes do respeito à propriedade privada em Durkheim (1950 [1890-1900]; 1968 [1912]) servem de linha norteadora para refletir sociologicamente sobre a construção do mercado dos bares pé-na-areia no litoral como um espaço particular de consumo, intermediado pela venda de comidas e bebidas e pelo fornecimento de serviços como infraestrutura, atendimento de garçons, acesso a banheiros na praia.

A ideia de festa em Durkheim permite a compreensão da festa popular da praia como um espaço e temporalidade distintos da vida cotidiana/laboral/mercadológica, cujo acesso é gratuito para todos os gru- pos que querem ir à praia, sejam turistas ou moradores-frequentadores. Em contraposição, a festa privada na forma dos bares pé-na-areia insere os proprietários dos bares e seus funcionários como novos atores sociais nesta coletividade, criando novos espaços e temporalidades mais próximos da vida cotidiana/laboral/mercadológica: enquanto do lado dos moradores frequentadores há uma oscialação maior entre o tempo do lazer da alta temporada e o trabalho, do lado dos proprietários dos bares estes dois tempos se sobrepõem.

A ideia de festa privada, além de complexificar a lógica do tempo da alta temporada e do tempo de trabalho, insere as transações econômicas nas relações sociais do uso da praia com fins de consumir comida e bebidas. No entanto, uma primeira observação sobre as avaliações dos usuários dos bares (sejam eles turistas ou moradoresfrequentadores) é a de que o caráter estritamente econômico, que estaria associado aos preços dos produtos e serviços, recebe pouco destaque, sendo mais evidenciada uma forte associação entre contentamento e elementos contratuais que regem uma relação de consumo no setor de alimentação: higiene, estrutura, qualidade da comida e do serviço. Do lado dos proprietários, há uma denegação do interesse econômico de lucro.

A ideia do respeito à propriedade privada em Durkheim (1950 [1890-1900]) é um caminho para analisar o contencioso referente à ameaça de demolição dos 48 bares da Sarney. Os limites entre o que é público e o que é privado perspassam a ideia de que o respeito à propriedade privada opera na esfera do sagrado. Isso ocorre a partir da crença compartilhada no poder de consagração e de ourtoga do Estado, que define, através dos seus agentes estatais, os limites 
entre o público e o privado.

0 espaço da praia consiste em um espaço de natureza, público e com acesso gratuito. Os limites desta crença compartilhada, objetivada em nossa Constituição Federal, ficam mais tênues com a questão da demolição dos bares pé-na-areia, na qual se evidencia: de um lado, o argumento ambiental (por parte do Estado) de que os bares pé-na-areia estão em área de preservação ambiental; do outro lado, o argumento econômico (por parte dos proprietários) de que os bares geram emprego, renda e contribuem para o mercado do turismo da região. Os escritos de Durkheim (1950 [18901900]) sobre a propriedade privada nos dão um norte para pensarmos este contencioso da demolição não apenas pelos discursos morais, que se dividem entre a ocupação pública ou privada; ao compreendermos a dinâmica de funcionamento do contencioso podemos também compreender as possíveis transformações (ocorridas no seio das disputas jurídicas do Estado) da fonte da confiança que sustenta a crença compartilhada sobre o que especificamente da natureza pertence a todos, em oposição ao que especificamente da natureza é privado e pertence ao mercado. Esta última questão merece ser melhor desenvolvida, particularmente pela ótica de uma Sociologia Econômica do Litoral, inspirada em Durkheim, para que possamos compreender o surgimento, as configurações e as reconfigurações dos mercados no litoral, considerado como um espaço que expressa não apenas os limites geográficos entre a terra e o mar, mas também os limites de confıguração entre público e privado e entre gratuito e pago na sociedade brasileira.

\section{Referências}

ALVES, M. Música, galera animada e comilança na areia. Diarinho. 26 de Novembro de 2016.

BEZERRA, E., D; SILVA, D. E. P. Da Adoção de inovações em serviços turísticos: Um estudo de múltiplos casos em bares e restaurantes da orla de Aracaju (SE, Brasil). Revista Brasileira de Pesquisa em Turismo, São Paulo, n.07, v.01, pp 14-34, jan./abril 2013.

BIDET, J.; DEVIENNE, E. Plages, territoires contestés. Actes de la Recherche em Sciences Sociales, n. 218, 2017.

BOURDIEU, P. La production de la croyance contribution à une économie des biens symboliques. ARSS, n.13, pp. 3-43., 1977,

BOURDIEU, P. La fausseté universelle de la conscience calculatrice. Anthropologie Économique - Cours au Collège de France (1992-1993), Paris: Raisons d'agir/Seul, 2017 [1992-1993].

BRUNO, Isabelle; SALLE, Grégory. État ne touche pas à mon matelas! Conflits d'usage et luttes d'appropriation sur la plage Pampelonne. In ARSS, v03, n.18, 2017.

CARDON, V. Des chiffres et des lettres. Évaluation, expressions du jugement de qualité et hiérarchies sur le marché de l'hôtellerie'. Réseaux, n.183, 2014.

CASTRO, S. F. L. de; SOUTO, W. Sol e praia: orientações básicas. Ministério do Turismo, Secretaria Nacional de Políticas de Turismo, Departamento de Estruturação, Articulação e Ordenamento Turístico, Coordenação Geral de Segmentação - 2ed. - Brasília, Ministério do Turismo, 2010. $59 \mathrm{p}$.

CMI Brasil. Rio de Janeiro- RJ: Farofaço 0.2: Nós vamos invadir a nossa praia. CMI Brasil. 04 de Outubro de 2015.

CROZAT, M. D ; FOURNIER, S. De la fête aux loisirs: évènement, marchandisation et invention des lieux. In Ann. Géo, n. 643, 2005, pp. 307-32. 
DURKHEIM, E. Le droit de Proprieté. IN: DURKHEIM, E. Leçons de Sociologie. Physique des moeurs et du droit. 1890-1900. [Edição publicada em 1950]

DURKHEIM, E. Da divisão do trabalho social. São Paulo : Martins Fontes, 1999 [1893].

DURKHEIM, E. Répresentations individuelles et répresentations collectives. Révue de métaphysique et de morale, v. 6, 1898.

DURKHEIM, E. Les formes élémentaires de la vie religieuse. Le Système Totémique en Australie.

Livre III. Paris. Les presses universitaires de France, 1968 [1912]

FRANÇA, S. L. A. A produção do espaço na zona de expansão de Aracaju/SE: dispersão urbana, condomínios fechados e políticas públicas. Dissertação de Mestrado em Arquitetura e Urbanismo. Universidade Federal Fluminense, Agosto de 2011.

FOURCADE, M. Cents and Sensibility: Economic Valuation and the Nature of "Nature". American Journal of Sociology. V.116, n.06, 2011.

KRIPPENDORF, J. Sociologia do Turismo: para uma nova compreensão do lazer e das viagens. São Paulo: Aleph, 3a edição, 2003 [2001], 184p.

LIMA, Letícia B de M ; VILAR, José W. C. A aplicação do TALC no destino turístico de sol e praia no litoral sul de Sergipe, Brasil. Caderno Virtual de Turismo,v.14, n.03, 2014.

LOLOUM, T. Derrière la plage, les plantations. Ethnographie d'une "situation touristique» dans le Nordeste brésilien: La cas de Tibau du Sul, RN. Tese de doutorado. École des Hautes Études en Sciences Sociales e Université de Lausanne, 2015. MARINHO, A; PIMENTEL, G.G.A. Dos clássicos aos contemporâneos: revendo e conhecendo importantes categorias referentes às teorias do lazer. In PIMENTEL, G.G.A. Teorias do Lazer. Maringá: Eduem, 2010. p.11-42.

PEREIRA, S. de A. Urbanização litorânea: o espaço "Orla de Atalaia". In Cidades e patrimônios culturais - investigações para a iniciação à pes- quisa. LEITE, R.P; SOUZA, E.C.M (Orgs). Editora UFS: Aracaju, 2013.

PROVINCIALI, V.L.N; SARAIVA, L.A.S. Gestión Ambiental en el sector de alimentos y bebidas en la costa de Aracaju (Sergipe-Brasil). Estudios y Perspectivas en Turismo, v.18, 2009, pp.176-192. SARTORE, M. A representação coletiva dos bares e restaurantes pé-na-areia produzida pelo dispositivo TripAdvisor: o caso de Aracaju-Sergipe. In Revista TOMO, N30, Jan-Jun 2017.

SEBILAU, A. Negócios no contra tempo e no contra espaço. Os mercados localizados no litoral:surf-shops e a formação de praticantes de windsurfe. Revista TOMO, no prelo, 2018.

URBAIN, J. Sur la plage - Moeurs et coutumes balnéaires (XIXe-Xxe siècles). Éditions Payot $\mathrm{t}$ Rivages, Paris, 1994. (Impresso pela CPI, Espanha, 2016).

VERA, L. A. R; LADEIRA, R; COSTA, A.S. A retirada das barracas de praia da orla de Salvador na perspectiva de turistas e moradores. Caderno Virtual de Turismo, Rio de Janeiro, v. 13, n. 3., p.308-323, dez 2013.

ZELIZER, V. Human Values and the Market: the case of life insurance and death in $19^{\text {th }}$-Century America. In The Sociology of Economic Life. Granovetter, M e Swedberg, R (orgs). San Francisco: Westview Press, 1992. Pp 285-306. 
RESUMO

Neste artigo, desenvolvo uma Sociologia Econônomica do Litoral para analisar a ocupação mercadológica da praia pelos bares pé-na-areia. Argumento que existem dois fenômenos que expressam o ato de comer e beber nas praias de Aracaju: a festa popular e a festa privada. A partir de observação direta, análise documental e entrevistas, este artigo caracteriza estes dois fenômenos em diálogo com a conceituação de festa e do respeito à propriedade privada do sociólogo Émile Durkheim. Concluo argumentando pela pertinência de qualificar o ato de comer e beber na praia enquanto festa, cuja lógica de funcionamento se reconfigura e se torna complexa com a existência dos bares pé-na-areia, sobrepondo-se as oposições trabalho-lazer, ocultando-se a finalidade econômica dos empreendimentos e, pela própria existência dos bares, evidenciando-se os conflitos do uso privado da praia, por consequência, da relação mercado e meio-ambiente.

\section{PALAVRAS-CHAVES}

Sociologia Econômica, Durkheim, Bares pé-na-areia, Festa; Mercado.

\section{Abstract}

In this article, weit was developed an Economic Sociology of the Coast to analyze the beach occupation by commerce focusing on beach bars as a case study. Two phenomena express the way people eat and drink while at the beaches of Aracaju: the free party and the private party. By direct observation, document analysis and interviews, this article characterizes these two phenomena in dialogue with the ideas of Émile Durkheim about the party and the source of respect for private property. In the conclusion, weit is argued about the relevance of qualifying these acts of eating and drinking on the beach as a party, in which the operating logic is reconfigured and becomes complex with the existence of beach bars, overlapping leisure-work oppositions, concealing predominantly economic rationales and, by the very existence of the beach bars, highlighting conflicts related to the private use of the beach, consequently, the relations between markets and environment.

\section{KEYWORDS}

Economic Sociology. Durkheim. Beach Bars. Party. Market. 


\section{RÉSUMÉ}

Dans cet article, je développe une sociologie économique du littoral a partir de l'occupation commerciale de la plage par des bars à la plage. Il existe deux phénomènes qui expriment l'acte de manger et de boire sur les plages de Aracaju: la fête populaire et la fête privée. En utilisant l'observation directe, l'analyse de documents et des entrevues, cet article présente ces deux phénomènes en dialogue avec la conceptualisation de fête et du respect de la propriété privée du sociologue Émile Durkheim. Je conclus en faisant valoir la pertinence de considérer l'acte de manger et boire sur la plage comme de la fête dont la logique s'est reconfiguré et devient complexe par l'existence des bars à la plage qui coïncident les temps de loisirs et le travail, qui dissimulent leur objectif économique. Leur propre existence met en évidence des conflits de l'usage privé et public de la plage et, en conséquence, des conflits entre le marché et l'environnement.

Mots-clés

Sociologie d'Économi. Durkheim. Bars à la plage. Fête. Marché

Recebido em: 08/01/2019

Aprovado em: 05/04/2019 